Original Article

\title{
Clinicopathological study of Lepromatous leprosy and Histoid leprosy in a Tertiary care Institute
}

\section{Sindhushree N}

Department of Pathology, Karnataka Institute of Medical Sciences, Hubballi, Karnataka, India

\author{
Keywords: \\ Grenz zone; \\ Histoid; \\ Histopathology; \\ Lepromatous leprosy; \\ Leprosy;
}

\begin{abstract}
Background: Lepromatous leprosy is a clinical course seen in patients with inefficient cellular immunity against Mycobacterium leprae, resulting in anergy. A highly bacilliferrous type of lepromatous leprosy is histoid leprosy. Histoid leprosy was initially reported to manifest after the failure of long-term dapsone monotherapy, irregular therapy, or inadequate therapy. However, it is now well known that histoid leprosy develops de-novo as well. This study was undertaken to know the incidence and clinicopathological characteristics of lepromatous leprosy and histoid leprosy.
\end{abstract}

Materials and Methods: This was a combined (both retrospective and prospective) study of lepromatous and histoid Leprosy, undertaken in the Department of Pathology, Karnataka Institute of Medical Sciences, Hubballi, over 42 months from January 2013 to June 2016.

Results: Out of the 16 clinically diagnosed lepromatous leprosy cases, only 5 were histologically proven to be the same. Of the seven clinically diagnosed histoid leprosy cases, 4 were histoid leprosy on histopathology and the remaining 3 were lepromatous leprosy. All 4 patients of histoid leprosy were cases of De- Novo histoid leprosy. The commonest skin lesion encountered were erythematous patches $(9 / 16)$ in lepromatous leprosy and nodules (5/7) in histoid leprosy.

Conclusions: Lepromatous leprosy when diagnosed in an early stage, interrupts the epidemiological chain and avoids the associated disabilities and psychological effects for the patient and family. Histoid leprosy is a rare entity that can also present with no history of prior anti-leprosy treatment, the diagnosis of "de-novo histoid leprosy" should be kept in mind.

\section{Correspondence:}

Dr. Sindhushree N

Department of Pathology,

Karnataka Institute of Medical Sciences, Hubballi, Karnataka, India

ORCID ID: 0000-0002-4757-1308

Email:dr.sindhu.kshitij@gmail.com

Reveived : October $10^{\text {th }} 2020$; Accepted : January $19^{\text {th }} 2020$

Citation: Sindhushree N. Clinicopathological study of Lepromatous leprosy and Histoid leprosy in a tertiary care Institute. J Pathol Nep 2021;11:1818-24.DOI: 10.3126/jpn.v11i1.31929

Copyright: This is an open-access article distributed under the terms of the Creative Commons Attribution 4.0 International License, which permits unrestricted use, distribution, and reproduction in any medium, provided the original author and source are credited.

\section{INTRODUCTION}

Leprosy, also known as Hansen's disease, is a chronic infectious disease caused by Mycobacterium leprae, a microorganism that has a predilection for the skin and nerves. The disease is clinically characterized by one or more of the three cardinal signs: hypopigmented or erythematous skin patches with definite loss of sensation, thickened peripheral nerves, and acid-fast bacilli on skin smear or biopsy material. ${ }^{1}$ Leprosy is almost exclusively a disease of the developing world affecting areas of Asia, Africa, Latin America, and the Pacific region. More than $80 \%$ of the 
worldwide cases occur in India, China, Myanmar, Indonesia, Brazil, Nigeria, and Nepal. ${ }^{2}$ Based on the immune response of the host, the concept of a continuous spectrum of leprosy has been developed. At one end is the tuberculoid form, with strong resistance and limited disease (i.e., tuberculoid pole), and at the other end is the lepromatous pole, with extensive, widespread involvement of the skin, nerves, upper respiratory tract, eyes, testes, etc. ${ }^{3}$

Lepromatous leprosy (LL) initially has cutaneous and mucosal lesions, with neural changes occurring later. The lesions usually are numerous and are symmetrically arranged. There are three clinical types: macular, infiltrative nodular, and diffuse. In the macular type, numerous illdefined, confluent, either hypopigmented or erythematous macules are observed. They are frequently slightly infiltrated. The infiltrative-nodular type, the classical and most common variety may develop from the macular type or arise as such. It is characterized by papules, nodules, and diffuse infiltrates that are often dull red. Involvement of the eyebrows and forehead often results in leonine facies, with a loss of eyebrows and eyelashes. The lesions themselves are not notably hypoesthetic, although, through the involvement of the large peripheral nerves, disturbances of sensation and nerve paralyses develop. The nerves that are most commonly involved are the ulnar, radial, and common peroneal nerves. The diffuse type of leprosy, called Lucio leprosy, which is most common in Mexico and also in Central America, shows diffuse infiltration of the skin without nodules. This infiltration may be quite inconspicuous except for the alopecia of the eyebrows and eyelashes it produces. ${ }^{4}$

LL in the usual macular or infiltrative nodular lesions, exhibits an extensive cellular infiltrate that is almost invariably separated from the flattened epidermis by a narrow grenz zone of normal collagen. In florid early lesions, the macrophages have abundant eosinophilic cytoplasm and contain a mixed population of solid and fragmented bacilli (BI $=4$ or 5 ). Lymphocyte infiltration is not prominent, but there may be many plasma cells. In time, and with antimycobacterial chemotherapy, degenerate bacilli accumulate in the macrophages the so-called lepra cells or Virchow cells which then have foamy or vacuolated cytoplasm. ${ }^{4}$ The detection of LL in large numbers is worrisome which could impede the aim of eradication of this infectious and ravaging disease. One such highly bacilliferrous type of leprosy is termed histoid leprosy. ${ }^{5}$

Histoid leprosy (HL) is a common disease in India, more prevalent in the southern part of the country. It was first described by Wade in 1960 . The term was coined after the classic histopathological appearance of histoid lesions, which have histiocytes that form interlacing bands, curlicues, and whorls. HL was initially reported to manifest after the failure of long-term dapsone mono-therapy, irregular therapy, or inadequate therapy. However, it is now well known that HL develops de-novo as well. HL is considered by some to be a subtype of LL, whereas others consider it to be an independent type. ${ }^{6}$

Clinically, the lesions appear as firm, erythematous, shiny, smooth, hemispheric, round to oval non-tender nodules on the background of normal skin located on the face, back, buttocks, and extremities as well as over bony prominences. When localized on the face, they have a characteristic centrofacial distribution. ${ }^{6}$ Histoid nodules can also represent the first sign of Subpolar lepromatous leprosy (LL). When monotherapy with sulfones was in use, the appearance of histoid lesions in treated LLs patients could represent the first clinical sign of sulfone resistance. When numerous, nodules have symmetric distribution, possibly clustering in groups. ${ }^{7}$ Occasionally, the lesions may appear pedunculated or ulcerated. The nodules may be superficially or deeply placed on the skin, or subcutaneous. Rare presentations include xanthomatous lesions, umbilicated nodules resembling molluscum contagiosum, and scrotal sinus. Two types of histoid facies can be seen. In one subgroup, the facies resemble that of LL, in which patients have an old, wrinkled, atrophic face with scanty eyebrows and depressed nasal changes with scant histoid lesions on the face. In the next subgroup, patients have histoid lesions on apparently normal skin with no nasal or ocular changes. ${ }^{6}$

Reaction episodes are considered to be uncommon in HL; however, episodes of Erythema nodosum leprosum (ENL) have been observed. The differential diagnosis includes progressive nodular histiocytosis, conventional leprosy nodules, molluscum contagiosum, and neurofibromas. ${ }^{6}$

The pathogenesis of this rare and unusual variant of leprosy remains unresolved. The interplay of genetic factors, immune response, and treatment received in a given patient seem to influence the manifestations of HL. ${ }^{8}$ Microscopically, the dermis shows sheets of round to spindle-shaped histiocytes, with a pattern resembling benign fibrous histiocytoma and a high Bacillary index (BI) of $5+$ or $6+.^{9}$ The incidence of this rare type of leprosy has been reported to vary from $2.79 \%$ to $3.60 \%$ among total leprosy patients. The absence of anaesthetic patches and deformities yet being highly infectious sets this type of leprosy apart from other types thereby posing a high risk of transmission to other members of the family. ${ }^{5}$ Here we attempted to know the incidence and clinicopathological features of LL and HL.

\section{MATERIALS AND METHODS}

The present research was a (retrospective and prospective) study, undertaken in the department of Pathology, Karnataka Institute of Medical Sciences, Hubballi, over a period of 42 months from January 2013 to June 2016. Punch biopsies were taken from clinically diagnosed and clinically suspected cases of LL \& HL and stained by HematoxylinEosin (HE) \& Fite-Faraco (FF) stain. A brief clinical history, 


\begin{tabular}{lcc}
\multicolumn{3}{l}{ Table 1. Clinical types of leprosy } \\
\hline Clinical Types & No of patients & Percentage \\
\hline IL & $\mathbf{4}$ & $\mathbf{1 . 4 3}$ \\
\hline TT & 8 & 2.86 \\
\hline BT & 95 & 33.93 \\
\hline BB & 12 & 4.30 \\
\hline BL & 16 & 5.71 \\
\hline LL & 16 & 5.71 \\
\hline HL & 7 & 2.5 \\
\hline Type $\mathbf{1}$ reaction & 3 & 1.07 \\
\hline Type 2 reaction & 20 & 7.14 \\
\hline NS & 58 & 20.71 \\
\hline Relapse & 41 & $14.64 \%$ \\
\hline Total & $\mathbf{2 8 0}$ & $\mathbf{1 0 0 \%}$ \\
\hline
\end{tabular}

NS - Not specified (clinical type)

examination findings indicating signs and symptoms of the skin lesions were collected. Histopathological findings and bacillary index were noted.

\section{RESULTS}

A total of 280 leprosy patients were enrolled in the leprosy clinic from January 2013 to June 2016. The percentages of different types of leprosy observed clinically as shown below in Table 1. Sixteen cases were diagnosed clinically as having LL and seven cases as HL, resulting in an incidence of $5.71 \%$ of LL and $2.5 \%$ of HL among leprosy cases. (Table 1)

In the present study, male to female ratio was 5:3 in LL with

Table 2. Clinical features of Lepromatous leprosy $(n=16)$

\begin{tabular}{|c|c|c|c|c|c|}
\hline S. $\mathbf{N}$ & Age/Sex & Lesion type & LOS & NT & CD \\
\hline 1 & $36, \mathrm{M}$ & CL & - & + & $\mathbf{L L}$ \\
\hline 2 & $53, \mathrm{M}$ & $\mathrm{EP}$ & - & + & $\mathrm{LL}$ \\
\hline 3 & $55, \mathrm{~F}$ & HP & - & + & $\mathrm{LL}$ \\
\hline 4 & $30, \mathrm{M}$ & $\mathrm{CL}$ & - & + & LL \\
\hline 5 & $42, \mathrm{M}$ & $\mathrm{CL}$ & - & + & LL \\
\hline 6 & $50, \mathrm{~F}$ & Others & - & - & LL \\
\hline 7 & $32, \mathrm{M}$ & EP & - & + & LL \\
\hline 8 & $65, \mathrm{~F}$ & Others & - & + & LL \\
\hline 9 & $50, \mathrm{~F}$ & HP \& EP & - & + & $\mathrm{LL}$ \\
\hline 10 & $42, \mathrm{M}$ & EP & - & + & LL \\
\hline 11 & $35, \mathrm{~F}$ & $\mathrm{EP}$ & - & + & $\mathrm{LL}$ \\
\hline 12 & $70, \mathrm{M}$ & EP & - & - & LL \\
\hline 13 & $32, \mathrm{M}$ & EP & - & + & $\mathrm{LL}$ \\
\hline 14 & $55, \mathrm{~F}$ & EP & + & + & $\mathrm{LL}$ \\
\hline 15 & $40, \mathrm{M}$ & EP & + & + & LL \\
\hline 16 & $27, \mathrm{M}$ & EP & - & - & LL \\
\hline
\end{tabular}

CL-Combined lesions, EP-Erythematous patch, HP-Hypopigmented patch, LOS-Loss of sensation, NT-Nerve thickening, CD-Clinical diagnosis.
$10(62.5 \%)$ being males and $6(37.5 \%)$ being females. The youngest patient was 27 yrs old male and the oldest patient was $70 \mathrm{yrs}$ male in this study and the mean age was 44.62

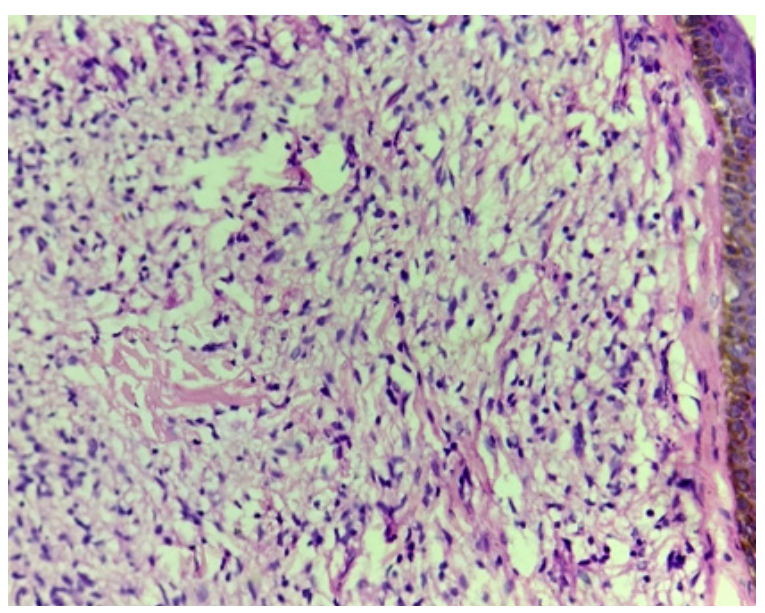

F igure 1: Lepromatous leprosy. Section showing atrophic epidermis, Grenz zone, and nodular aggregates of foamy cells. (H and E stain, x400)

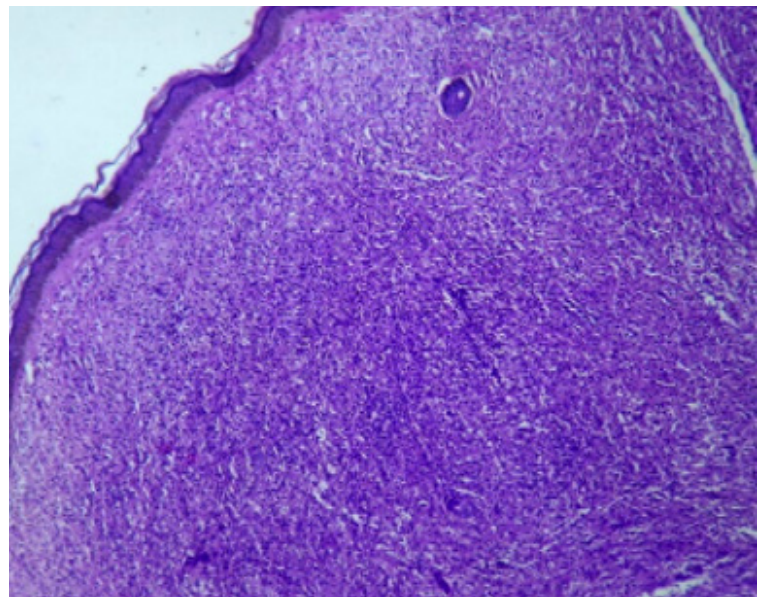

Figure 2: Histoid leprosy. Section showing spindle shaped cells arranged in fascicles ( $H$ and E stain $x$ 100)

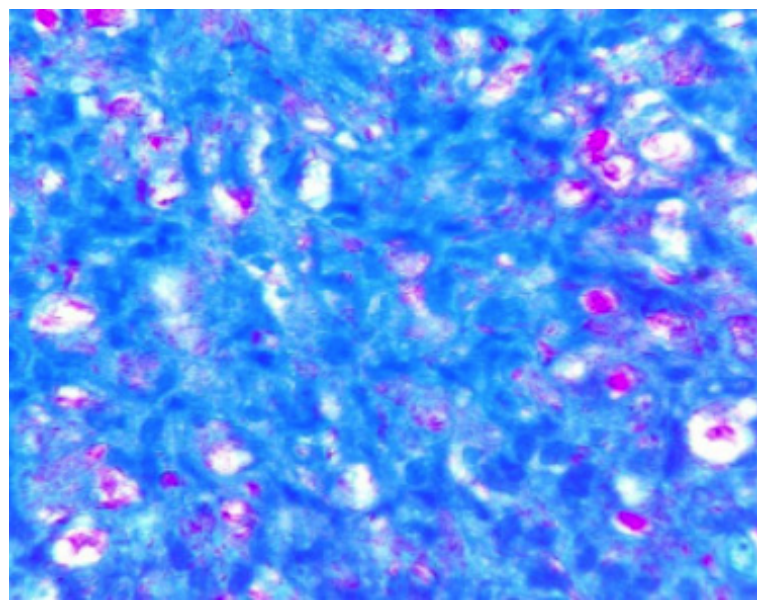

Figure 3. Histoid leprosy. Acid fast bacilli in clusters and Globi. (Modified Fite-Faraco stain, x 1000) 
Table 3. Clinical features of Histoid Leprosy $(n=7)$

\begin{tabular}{lccccc}
\hline S.N. & Age/ Sex & Lesion type and location & LOS & NT & CD \\
\hline $\mathbf{1}$ & $52, \mathrm{M}$ & $\mathrm{N}, \mathrm{UL}$ and LL & - & + & HL \\
$\mathbf{2}$ & $67, \mathrm{M}$ & $\mathrm{N}, \mathrm{UL}$ and LL & - & + & $\mathrm{HL}$ \\
\hline $\mathbf{3}$ & $30, \mathrm{M}$ & $\mathrm{N}$, Ear lobule and face & - & + & $\mathrm{HL}$ \\
$\mathbf{4}$ & $40, \mathrm{M}$ & $\mathrm{P}, \mathrm{UL}$ and LL & - & - & $\mathrm{HL}$ \\
$\mathbf{5}$ & $25, \mathrm{~F}$ & $\mathrm{~N}, \mathrm{~T}$ & - & $\mathrm{HL}$ \\
\hline $\mathbf{6}$ & $28, \mathrm{M}$ & $\mathrm{P}, \mathrm{UL}$ and LL & - & - & $\mathrm{HL}$ \\
$\mathbf{7}$ & $28, \mathrm{M}$ & $\mathrm{N}, \mathrm{T}$ & - & $\mathrm{HL}$ \\
\hline
\end{tabular}

$N$-nodule, P-Papule, UL- upper limb, LL- lower limb, T-trunk, LOS-Loss of sensation, NT-Nerve thickening, CD-Clinical diagnosis.

Table 4. Histopathological features and Bacillary index of Lepromatous leprosy

\begin{tabular}{|c|c|c|c|c|c|c|c|}
\hline S.N. & EA & EU/ BME & $\begin{array}{c}\text { Grenz } \\
\text { zone }\end{array}$ & Lymphocyte infiltrate & Macrophage infiltrate & BI & HD \\
\hline 1 & + & - & + & + & + & $6+$ & HL \\
\hline 2 & + & - & - & + & + & $1+$ & BT \\
\hline 3 & NA & NA & NA & NA & NA & NA & IB \\
\hline 4 & + & $\mathrm{EU}$ & + & + & & $6+$ & LL \\
\hline 5 & + & - & + & + & + & $5+$ & LL \\
\hline 6 & + & - & + & + & + & - & BT \\
\hline 7 & + & BME & - & + & + & $1+$ & TT \\
\hline 8 & + & - & + & - & + & +4 & LL \\
\hline 9 & + & - & + & - & - & - & $\mathrm{NE}$ \\
\hline 10 & + & - & + & - & + & +5 & LL \\
\hline 11 & + & - & + & - & + & +4 & LL \\
\hline 12 & + & - & - & + & - & - & BT \\
\hline 13 & + & - & - & + & - & - & BT \\
\hline 14 & + & - & - & + & + & - & IL \\
\hline 15 & + & EU & + & + & + & - & $\mathrm{BL}$ \\
\hline 16 & + & - & + & + & + & +4 & $\mathrm{BL}$ \\
\hline
\end{tabular}

EA-Epidermal atrophy, EU-Epidermal ulceration, BME-Basement membrane erosion, HD- Histopathological diagnosis.

Table 5. Histopathological features and Bacillary index of Histoid leprosy

\begin{tabular}{|c|c|c|c|c|c|c|c|}
\hline & $\begin{array}{l}\text { Epidermal } \\
\text { atrophy }\end{array}$ & Grenz zone & $\begin{array}{l}\text { Lymphocyte } \\
\text { infiltrate }\end{array}$ & $\begin{array}{c}\text { Macrophage } \\
\text { infiltrate }\end{array}$ & SSH & BI & HP \\
\hline 1 & + & + & + & + & + & $5+$ & HL \\
\hline 2 & + & + & - & + & - & $5+$ & LL \\
\hline 3 & + & + & + & + & + & $6+$ & HL \\
\hline 4 & + & + & - & + & - & $6+$ & LL \\
\hline 5 & + & + & - & + & + & $5+$ & HL \\
\hline 6 & - & + & - & + & - & $5+$ & LL \\
\hline 7 & + & + & - & + & + & $5+$ & HL \\
\hline
\end{tabular}

SSH- spindle shaped histiocytes, HP- Histopathological diagnosis

years as shown in Table 2. The commonest skin lesions encountered were erythematous patches in 9 cases out of 16 (56.25\%). Combined lesions (macules, papules \& nodules) were seen in 3 cases (18.75\%). Hypopigmented patches and combined hypopigmented \& erythematous patches were seen in 1 case each $(6.25 \%)$. The remaining 2 cases $(12.5 \%)$ had no skin lesions but other symptoms like tingling and numbness, burning sensation, difficulty in buttoning and unbuttoning, slippage of slippers, etc were present. Two or three peripheral nerves are involved in 13 patients, the most common being the ulnar nerve. No nerve thickening was seen in 3 cases. Two patients had a history of anaesthesia and deformities. Only one patient presented with a trophic ulcer. (Table 2)

In $\mathrm{HL}$, male to female ratio was $6: 1,6(85.72 \%)$ being 
males and $1(14.28 \%)$ being female. The youngest patient was $25 \mathrm{yrs}$ old female and the oldest patient was $67 \mathrm{yrs}$ male in the study and the mean age was 38.57 years as shown in Table 3.

The commonest skin lesions encountered were nodules over normal-looking skin in 5 cases out of $7(71.42 \%)$. Papules were seen in the rest of the 2 cases $(28.58 \%)$. The most common sites involved were upper and lower limbs in 4 cases $(57.14 \%)$, followed by the trunk in 2 cases $(28.58 \%)$. 1 patient presented with ear lobe infiltration and facial lesions. Two or three peripheral nerves are involved in 4 patients, the most common being the ulnar nerve. No nerve thickening was seen in 3 cases. Only one patient had a history of anaesthesia along with skin lesions. None of the patients had trophic ulcers or deformities or lepra reactions. It was seen that all 7 patients developed clinical lesions without receiving any treatment in the past in the form of Dapsone or Multidrug therapy. (Table 3)

Out of sixteen clinically diagnosed LL cases, each 1 case was of IL, TT, and HL, 4 cases of BT, 2 cases of BL, 5 cases of LL according to microscopy. No evidence of leprosy and inadequate biopsy were seen in 1 case each. The histopathological features included epidermal atrophy with a subepidermal grenz zone and macrophage granulomas composed of foamy macrophages with no epithelioid cells and a few lymphocytes. All 5 cases of LL (fig. 1) were positive for FF stain with BI of $5+\& 4+$ in each 2 cases and $6+$ in one case as shown in Table 4.

Out of seven clinically diagnosed HL cases, 4 were HL (fig. 2), and 3 were LL according to microscopy. The histopathological features included epidermal atrophy with a subepidermal grenz zone and a well-circumscribed dermal area of closely packed spindle-shaped histiocytes in a storiform pattern. All 4 cases were positive for FF stain (fig. 3 ) with the bacillary index of $5+$ in 3 cases and $6+$ in one case as shown in Table 5.

\section{DISCUSSION}

LL is the clinical course of patients infected by the disease, with inefficient cellular immunity against Mycobacterium leprae, resulting in anergy. This condition is described as an adult disease due to the long incubation period. ${ }^{10}$ The cell mediated immunity (CMI) is severely impaired in LL. This impairment results in the uncontrolled multiplication and dissemination of lepra bacilli. LL can appear de novo due to the highly anergic state of the individual or may downgrade from the BT or BL spectrum in the absence of treatment. LL with a de novo appearance is called polar LL (LLp), and when a result of downgrading, it is called subpolar LL (LLs). The subpolar group can regain its lost CMI and upgrade in the spectrum. FF stain reveals large numbers of acid-fast bacilli and globi. Also, bacteriologically, the subpolar group clears earlier than the polar group after therapy. LL is the most severe form of leprosy as it can involve almost any part of the human body. However, warm areas of the body such as the axillae, groin, perineum, and hairy scalp of the body are relatively spared, as lepra bacilli favor the cooler areas of the body. ${ }^{6}$

An untreated patient with LL has leonine facies (progressive induration, thickening, and nodulation of the face accentuate the skin folds), thickening and nodulations of ear lobes, and a broad and swollen nose, which may be a collapsed, thinning of eyebrows (superciliary madarosis) and eyelashes (ciliary madarosis), and may have characteristic facies leprosa. 'Facies leprosa' is characterized by the resorption of the nasal bone, anterior nasal spine, supra-incisive alveolar region, and anterior alveolar process of the maxilla, with associated sensory or motor damage depending on the type of nerve(s) involved. As a result of hematogenous dissemination, LL can affect several organ systems apart from the skin, including the eyes, bones, oral cavity, testes, reticulo-endothelial system, muscles, and bones. They can be affected directly by LL or secondarily in reaction episodes. ${ }^{6}$

The diagnosis, based on clinical suspicion, is confirmed through bacteriological and histopathological analyses (in which non-caseating granulomas are observed), as well as by means of the lepromin test (intradermal reaction that is usually negative in LL form and positive in the tuberculoid form). Histopathological differential diagnoses of both LL include mainly other diseases presenting foamy macrophages such as xanthomas and xanthogranulomas, post-kala-azar dermal leishmaniasis, paraffinoma, and rarely also infections caused by other non-tuberculous (atypical) mycobacteria. ${ }^{7}$

The prognosis of LL in the absence of treatment is poor. The disease progressively worsens and affects the entire body. The patient is left with many non-healing ulcers and several deformities. Even with the institution of treatment, remission is often punctuated by several episodes of type 2 reactions. Death from leprosy is mainly due to superadded infections, severe and recurrent type 2 reactions, amyloidosis, and renal failure. ${ }^{6}$ The incidence of LL in the present study was $5.71 \%$ which is comparable to another study by Veena et al.11 (5.5\%). However, the study by Ankur et al.12 (9.92\%) showed a higher incidence of LL.

The incidence of $\mathrm{HL}$ in India has been reported to vary from 2.79 to $3.60 \%$ among the total leprosy patients with a male preponderance, the average age at diagnosis was between 21 to 40 years. ${ }^{5}$ In the present hospital-based study of clinically, histopathologically, and bacteriologically confirmed cases of HL revealed the incidence of HL in this part of Karnataka as $2.5 \%$, in close agreement with the incidence data from other studies by Mendritta et al. ${ }^{13}(1.14 \%)$, Punia et al. ${ }^{14}$ (3.37\%) and Girish Kumar et al. ${ }^{5}$ (4.7\%) in various parts of India. 
There was a male preponderance among HL patients, in the present study with M:F ratio of 6:1. Male preponderance was also seen in studies by Kaveri et al.15 (7:1), Girish Kumar et al. ${ }^{5}$ (3:1), Mendritta et al. ${ }^{13}$ (4.5:1), and Punia et al. ${ }^{14}(2.2: 1)$. The male preponderance could probably be due to an increased chance of exposure to infectious cases at the workplace and while travelling. ${ }^{15}$ In this study $20-40$ years age group accounted for the maximum number of cases ( 5 cases, $71.42 \%$ ) with a mean age group of 38.57 , which is similar to other studies by Girish Kumar et al. ${ }^{5}$, Mendritta et al. ${ }^{13}$ and in contrast to studies by Kaveri et al. ${ }^{15}$, and Punia et al. ${ }^{14}$ in which 40-60 yr age group was most commonly affected. Mendritta et al. ${ }^{13}$ reported the youngest patient of HL in a 14 yrs old patient, whereas Punia et al. ${ }^{14}$ and Girish Kumar et al. ${ }^{5}$ found HL in the 11 yrs and 20 yrs of age respectively. The youngest patient found in our study was 25 yrs of age.

All the seven cases of HL, in our study were previously untreated, and the mode of development was de-novo occurrence. This finding suggests that HL may not necessarily be due to drug resistance as has been previously postulated, and it could be a distinct form of leprosy as suggested by many authors and should not always be considered as a variant of LL. ${ }^{5}$

HL presents with 3-50 cutaneous or subcutaneous nodules especially over the extensor aspects of the extremities, back, buttocks, and face. They may be localized to bony prominences such as around the elbows and knees. The nodules are erythematous, shiny, succulent, globular, and protuberant, and arise from apparently normal skin. On the face, they can be seen in clusters on the middle of the forehead, cheeks, tip of the nose, and on the chin; the ears may be unaffected. In a widespread eruption, the mucosa of the oral cavity, hard palate, and glans penis may be involved. A slit skin smear from histoid lesions shows abundant AFB occurring in clusters, singly or tightly, packed in macrophages. ${ }^{3}$ In the present study, 5 out of 7 clinically diagnosed HL cases presented with non-tender, shiny nodules over apparently normal-looking skin, and the remaining 2 patients complained of papules. The most commonly involved site was the upper limb and lower limb and trunk followed by the face which is similar to studies by Girish Kumar et al. ${ }^{5}$, Kaveri et al. ${ }^{15}$, and Punia et al. ${ }^{14}$ On the contrary Mendritta et al. ${ }^{13}$ reported face as the commonest site of involvement. In this study, none of the patients had mucosal involvement. In the present study, two or three peripheral nerves involved in 4 patients, the most common being the ulnar nerve which is similar to studies by Girish Kumar et al. ${ }^{5}$, Kaveri et al. ${ }^{15}$, Mendritta et al. ${ }^{13}$ None of the patient had trophic ulcer or deformities in our study compared to the study of Girish Kumar et al. ${ }^{5}$, where 1 patient had claw hand deformity.

ENL is considered to be extremely uncommon in HL. There are only a few published case reports of ENL developing in patients with HL. ${ }^{15}$ None of the patients in this study reported type 1 or 2 reactions is similar to the study done by Kaveri et al. ${ }^{15}$ However study by Mendritta et al. ${ }^{13}, 3$ out of 11 and Girish Kumar et al. ${ }^{5}, 3$ out of $20 \mathrm{HL}$ patients had ENL.

The macrophage reaction is unusual in that the cells frequently become spindle-shaped and oriented in a storiform pattern, similar to those of a fibrohistiocytoma. The epidermis may be stretched over such dermal expansile nodules. 4 Histoid lepromas, unlike ordinary lepromatous lesion, grow in expansile rather than an infiltrative fashion. It resembles a tissue forming process rather than granuloma. The classical feature is the presence of numerous, thin, spindle-shaped histiocytes forming interlacing bands, whorls, and at times tight curlicules. In most cases, a free subepidermal grenz zone (band of Unna) is present. Histoid lesions can also have lymphocytes and occasionally, polymorphonuclear leukocytes, especially at the periphery of the lesion. ${ }^{3}$ There are three histological variants of histoid Hansen's, namely, pure fusocellular, fusocellular with epithelioid component, and fusocellular with vacuolated cells. The third pattern is most commonly observed. A peculiar phenomenon the tuberculoid contamination may be seen in cases of subcutaneous histoid lepromas. This is because of the occurrence of well-defined foci of epithelioid cells, located within the lesion substance or in the encircling fibrous tissue encapsulation. No satisfactory explanation of their occurrence is postulated, but it is likely that tuberculoid contamination may well represent the tuberculoid component of the earlier borderline leprosy. ${ }^{14}$

In the present study, out of seven clinically diagnosed HL cases, 4 were HL and 3 were LL according to microscopy. The histopathological features included epidermal atrophy with a subepidermal grenz zone and a well-circumscribed dermal area of closely packed spindle-shaped histiocytes in a storiform pattern.

HL shows the highest loads of bacilli (the BI is frequently 6), and the majority are solid staining, arranged in clumps like sheaves of wheat.4 In this study, FF stain showed BI of $5+$ in 3 cases and $6+$ in one case with the mean being 5.25 whereas the study by Kaveri et al ${ }^{15}$. showed BI ranging from $4+$ to $6+$ with a mean of 5.12 .

\section{CONCLUSIONS}

LL, diagnosed in an early stage of the disease, interrupts the epidemiological chain and avoids the frightening associated disabilities which end in social inability, with all the psychological effects for the patient and the family.

$\mathrm{HL}$ is a distinct rare form of multibacillary leprosy with characteristic clinical, bacteriological and histopathologic features. Being a rare entity patient presenting with the sudden eruption of multiple shiny nodules and papules 
over normal-looking skin with no history of taking antileprosy treatment diagnosis of "de-nova histoid leprosy" should be kept in mind and can be confirmed by its unique histopathological and bacteriological features.

\section{Acknowledgment}

The author is thankful to Karnataka Institute of Medical Sciences, Rajiv Gandhi University of Health Sciences, Hubballi- 570028, Karnataka, India.

\section{Conflict of interest: None}

\section{REFERENCES}

1. Bhat RM, Prakash C. Leprosy: An Overview of Pathophysiology. Interdisciplinary Perspectives on Infectious Diseases 2012: 1-6. Crossref

2. Gelber RH. Leprosy, In: Longo DL, Fauci AS, Kasper DL, Hauser SL, Jameson JL, Loscalzo J (eds). Harisson's principles of internal medicine. 18th edn. Mc-Graw Hill: New York; 2012. pp 1359-67.

3. Sharma VK, Malhotra AK. Leprosy: Classification and clinical aspects, In: Valia RG, Valia AR (eds). IADVL Textbook of Dermatology. 3rd edn. Bhalani Publishers: Mumbai; 2008: pp 203269.

4. Lucas S. Bacterial diseases, In: David E. Elder MB, Elentisas R, Johnson BL, Murphy GF (eds). Levers Histopathology of the Skin. 9th edn. Lippincott Williams \& Wilkins: Philadelphia, Pa, USA; 2005. pp 570- 578 .

5. G Ambade, A Asia. ClinicoEpidemiological Profile of Histoid Leprosy: A Prospective Study. Natl J Integr Res Med 2018; 9(1): 1619. $\underline{\text { Crossref }}$
6. Kumar DP, Uprety S, Dogra S. Clinical Aspects, In: Scollard D.M. and Gillis T.P., (eds). International Textbook of Leprosy; 2016. $\underline{\text { Website }}$

7. Nunzi E, Massone $\mathrm{C}$ and Noto S. Clinical Features, In: Nunzi E, Massone C, (eds). Leprosy: A practical guide: 1st edn. Springer: Berlin/Heidelberg, Germany; 2012. pp 115-137.

8. Rinasari U, Sawitri, Listiawan MY, Prokoeswa CRS, Agusni I, Santoso R et al. Histoid Leprosy- A case report. Indonesian Journal of Tropical and Infectious disease 2010; 1: 27-31. Crossref

9. Rosai J. Skin: Dermatoses, Tumors and tumor like conditions, In: Rosai J (eds). Rosai and Ackerman's surgical pathology. 10th edn. Mosby: Edinburg; 2011. pp 100.

10. Dorileo GB, Cavalcante LRS, Lopes JC, Damazo AS. Report of two cases of lepromatous leprosy at an early age. International Journal Of Infectious Diseases 2020; 101: 46-48. Crossref

11. Shivamurthy V, Gurubasavaraj H, Shashikala PS, Kumar P. Histomorphological study of leprosy. Afr J Med Health Sci 2013; 12(2): 68-73. DOI: 10.4103/2384-5589.134893 Crossref

12. Kumar A, Negi SR, Vaishnav K. A study of Clinico-histopathological correlation of leprosy in a tertiary care hospital in western district of Rajasthan. J Res Med Den Sci 2014; 2(3): 43-48. Crossref

13. Mendiratta V, Jain A, Chander R, Khan A, Barara M. A nine-year clinico-epidemiological study of Histoid Hansen in India. J Infect Dev Ctries 2011; 5(2): 128-131. Crossref

14. Punia R.P.S., Dhingra H, Baliyan A, Handa U, Mohan H, Thami G.P. Clinicopathologic Spectrum of Histoid leprosy. International Journal of Current Research 2017; 9(5): 50765-9. Website

15. Kaveri M, Wali VV. Clinico-pathological study of cases of histoid leprosy. Int J Res Dermatol 2020; 6:474-8. Crossref 